\title{
Plasma secretory phospholipase A2-lla as a potential biomarker for lung cancer in patients with solitary pulmonary nodules
}

\author{
Elena Kupert ${ }^{1}$, Marshall Anderson'1 ${ }^{1}$ Yin Liư ${ }^{2}$, Paul Succop ${ }^{3}$, Linda Levin ${ }^{3}$, Jiang Wang ${ }^{2}$, \\ Kathryn Wikenheiser-brokamp ${ }^{2}$, Pingping Chen ${ }^{4}$, Susan M Pinney ${ }^{3}$, Trudy Macdonald ${ }^{3}$, Zhongyun Dong ${ }^{4}$, \\ Sandra Starnes ${ }^{5}$ and Shan Lü ${ }^{2^{*}}$
}

\begin{abstract}
Background: Five-year survival for lung cancer has remained at $16 \%$ over last several decades largely due to the fact that over $50 \%$ of patients are diagnosed with locally-advanced or metastatic disease. Diagnosis at an earlier and potentially curable stage is crucial. Solitary pulmonary nodules (SPNs) are common, but the difficulty lies in the determination of which SPN is malignant. Currently, there is no convenient and reliable biomarker effective for early diagnosis. Secretory phospholipase A2-Ila (SPLA2-Ila) is secreted into the circulation by cancer cells and may allow for an early detection of lung cancer.

Methods: Plasma samples from healthy donors, patients with only benign SPN, and patients with lung cancer were analyzed. Expression of sPLA2-lla protein in lung cancer tissues was also determined.

Results: We found that the levels of plasma sPLA2-lla were significantly elevated in lung cancer patients. The receiver operating characteristic curve analysis, comparing lung cancer patients to patients with benign nodules, revealed an optimum cutoff value for plasma sPLA2-Ila of $2.4 \mathrm{ng} / \mathrm{ml}$ to predict an early stage cancer with $48 \%$ sensitivity and $86 \%$ specificity and up to $67 \%$ sensitivity for T2 stage lung cancer. Combined sPLA2-Ila, CEA, and Cyfra21.1 tests increased the sensitivity for lung cancer prediction. High level of plasma SPLA2-lla was associated with a decreased overall cancer survival. sPLA2-lla was overexpressed in almost all non-small cell lung cancer and in the majority of small cell lung cancer by immunohistochemistry analysis.
\end{abstract}

Conclusion: Our finding strongly suggests that plasma sPLA2-lla is a potential lung biomarker to distinguish benign nodules from lung cancer and to aid lung cancer diagnosis in patients with SPNs.

\section{Background}

Lung cancer is the leading cause of cancer death worldwide with 159,390 deaths in the US in 2009. This represents $30 \%$ of total cancer deaths [1]. The 5 -year survival rate is only $16 \%$, which has not changed in three decades. One key to improving lung cancer survival is to diagnose it at an earlier stage, given that the 5-year survival rate with stage $1 \mathrm{~A}$ non-small cell lung cancer (NSCLC) is as high as 73\% [2]. Advanced imaging technology and widespread availability of low dose spiral

\footnotetext{
* Correspondence: shan.lu@uc.edu

${ }^{2}$ Department of Pathology, University of Cincinnati College of Medicine, UC Metabolic Diseases Institute, 2120 E. Galbraith Road, Building A, Room 259, Cincinnati, OH 45237-0507, USA

Full list of author information is available at the end of the article
}

computed tomography (LDCT) have led to a significant increase in detection of lung nodules $[3,4]$. The prevalence of solitary pulmonary nodules (SPNs), (by definition, a SPN is $<3 \mathrm{~cm}$ in diameter), is $10 \sim 20 \%$ nationwide and up to $61 \%$ in the Ohio valley [5]. The majority of these nodules are benign, even among patients at increased risk for lung cancer such as smokers. The difficulty lies in the determination of which SPN is malignant. An increase in the size of a SPN by repeated CT scans is currently one important parameter to predict the presence of malignancy [6,7]. SPNs can be challenging to manage and costly to monitor with radiation exposure of repeat $\mathrm{CT}$ scans and potential morbidity of biopsy or surgical resection of benign

\section{Biomed Central}


nodules. In North America, surgical resection of a lung nodule alone costs more than $\$ 20,000$ [8]. Identification of malignant nodules is crucial because they represent a localized and potentially curable form of lung cancer. A few plasma biomarkers have been used to screen and diagnose cancers [9-11]. Currently, there is no single inexpensive, convenient, and reliable biomarker proven effective for the diagnosis of lung cancer [12].

Secretory phospholipase A2-IIa (sPLA2-IIa) is a phospholipid hydrolase enzyme that mediates the release of arachidonic acid (AA) and lysophosphatidylcholine, which are the precursors of eicosanoids and plateletactivating factor, respectively $[13,14]$. Eicosanoids are products of both sPLA2-IIa and cyclooxygenase-2 (Cox2 ) and exert control over many physiologic processes, such as inflammation, immunity, and tumorigenesis. It was reported that elevated eicosanoids, such as prostaglandins, are involved in the pathogenesis of lung cancer [15]. sPLA2-IIa is a downstream effector of the NF-kB gene $[16,17]$. A few early studies have demonstrated that sPLA2-IIa is overexpressed in almost all human prostate cancer specimens and elevated levels of sPLA2-IIa are associated with tumor grade [18-20]. sPLA2-IIa remains elevated in androgen-independent prostate cancers failing hormonal therapy and functions as a growth factor to stimulate growth in prostate cancer cells [21].

We recently reported that elevated signaling of the HER/HER2-PI3K-Akt-NF-kB pathway contributes to sPLA2-IIa overexpression and secretion in prostate cancer cells $[17,22,23]$. We confirmed that sPLA2-IIa secreted by cancer cells into the circulation to a detecTable level in mice carrying xenograft human tumor. We are the first to demonstrate that there are high levels of plasma sPLA2-IIa in prostate cancer patients, which are associated significantly with high Gleason score and advanced disease stage. In the present study, we expanded our observation to lung cancer. We found that lung cancer tissues overexpress sPLA2-IIa and high levels of plasma sPLA2-IIa may serve as a plasma biomarker for lung cancer.

\section{Methods}

\section{Patient population}

The study was conducted in accordance with the Declaration of Helsinki and the local Institutional Review Board approved the study protocol. All the specimens for this study were archived biospecimens with de-identified patient information. As part of the University of Cincinnati Thoracic Tumor Registry, plasma samples were collected pre-operatively from patients with pulmonary nodules known or suspected to be lung cancer undergoing resection (Principal investigator: Dr. Sandra Starnes) [5]. Data on final pathology of the resected nodules was collected and defined as the benign nodule- lung cancer cohort (BNLCC). Plasma samples were also collected from lung cancer patients from the "Genetic Epidemiology of Lung Cancer" cohort (GELCC; PI: Dr. Marshall Anderson), a familial lung cancer cohort. Plasma samples from healthy donors were obtained from the Cincinnati Hoxworth Blood Center.

\section{Reagent}

The mouse sPLA2-IIa antibody is a custom antibody developed in our lab. Human sPLA2-IIa antibody for Immunohistochemical (IHC) was from LifeSpan BioSciences (Seattle, WA).

\section{Enzyme-linked immunosorbent assay (ELISA)}

sPLA2-IIa levels in plasma samples were determined by ELISA kit (Catalog No. 585000, Cayman Chemical Company). All plasma samples were diluted ten times for ELISA as described before [17]. The concentration of sPLA2-IIa in plasma was tested in duplicate and determined against a standard curve for each ELISA assay. ELISA kits for Carcinoembryonic Antigen (CEA) (EIA1871) and Cytokeratin-19 fragment (CYFRA 21.1) (EIA3943) were purchased from DRG International Inc., USA. Plasma samples were subjected to CEA and Cyfra21.1 ELISA and quantitated against a standard curve of each ELISA assay.

\section{Immunohistochemical (IHC) staining}

Lung disease spectrum tissue array was obtained from Biomatrix.US (Rockville, MD). Immunohistochemistry (IHC) for the sPLA-IIa protein was performed as detailed in our previous studies [17,24]. Briefly, paraffinembedded tissue sections were deparaffinized in xylene, rehydrated in graded alcohol, and transferred to PBS. The slides were treated with a citric acid-based antigenretrieval buffer (DAKO Co., Carpinteria, CA), followed by $3 \% \mathrm{H}_{2} \mathrm{O}_{2}$ in methanol, incubated in blocking buffer (5\% BSA and 5\% horse serum in PBS) and then in the blocking buffer containing the primary antibody. After washing, the slides were incubated with a biotinylated secondary antibody (BioGenex Laboratories, San Ramon, $\mathrm{CA})$, followed by washing and incubation with the streptavidin-conjugated peroxidase (BioGenex). A positive reaction was visualized by incubating the slides with sTable diaminobenzidine and counterstaining with Gill's hematoxylin (BioGenex) and mounted with Universal Mount mounting medium (Fisher Scientific, Pittsburgh, PA). The intensity and extent of positive labeling for sPLA2-IIa in tissue arrays were assessed semiquantitatively and scored as 0 (no staining), $1+$ (weak and focal staining in $<25 \%$ of tissue), $2+$ (moderate intensity in $25-50 \%$ of tissue), $3+$ (moderate intensity in $>50 \%$ of tissue), and $4+$ (strong and diffused staining in $>50 \%$ of tissue). 


\section{Statistical Analysis}

The means and standard deviations were calculated with confirmed significant difference in plasma sPLA2-IIa level between lung cancer specimens and benign nodule specimens. Geometric means and standard deviations were also calculated with confirmed significant difference in plasma sPLA2-IIa level between lung cancer specimens and clinical control specimens. Unpaired $t$ test with Welch correction was performed to evaluate the difference between sPLA2-IIa means of (i) 96 lung cancer specimens versus 29 benign SPN specimens from the BNLCC; (ii) 44 T1 stage lung cancer specimens versus 18 T2 stage lung cancer specimens from the BNLCC; (iii) 44 lung cancer specimens from the GELCC versus 29 benign SPN specimens from the BNLCC. Unpaired t test with Welch correction was also used to analyze overall cancer survival year associated with plasma sPLA2-IIa level from the BNLCC.

A parametric Receiver Operating Characteristic (ROC) analysis of plasma sPLA2-IIa values was performed to evaluate the ability of the levels of plasma sPLA2-IIa to distinguish 96 patients with lung cancer from 29 patients with benign SPNs from the BNLCC. 44 lung cancer specimens from the GELCC relative to 29 benign SPNs specimens from the BNLCC were also subjected to the ROC analysis. The optimum cutoff value of plasma sPLA2-IIa was determined by calculating the Youden Index [25], which separated the combined set of SPLA2-IIa values into two groups, such that the number of correctly classified specimens was maximized, and the associated sensitivity and specificity for predicting lung cancer versus non-malignant nodule were determined.

\section{Results}

The levels of plasma sPLA2-Ila are increased in lung cancer patients

The means and standard deviations of plasma sPLA2-IIa levels from 96 patients with lung cancer and 29 patients with benign lung nodules (SPNs) from the BNLCC were $3646 \pm 407.3$ and $1772 \pm 306.8 \mathrm{pg} / \mathrm{ml}$, respectively (Table 1 and 2, and see Additional file 1). Based on an unpaired t-test, the average plasma sPLA2-IIa level in lung cancer patients was significantly higher than that in the non-malignancy SPN controls $(P=0.004)$. The optimum cutoff value of plasma sPLA2-IIa by ROC analysis was $2.4 \mathrm{ng} / \mathrm{ml}$, which resulted in $48 \%$ sensitivity and $86 \%$ specificity for predicting the presence of lung cancer (Figure 1a and Table 3). The area under the curve (AUC) was 0.68 (95\% CI: $0.58 \sim 0.79$ ) (Figure 2b). We also analyzed 44 lung cancer samples from the GELCC in which mean and standard deviation of plasma sPLA2-IIa were $3718 \pm 407.8$ (see Additional file 2). The average plasma sPLA2-IIa level in these lung cancer patients was also significantly higher than that in
Table 1 Characteristics of the patients

\begin{tabular}{lcc}
\hline BNLCC-Lung cancer & 96 \\
\hline M/F & $37 / 59$ \\
\hline Mean age year (range) & $64(41 \sim 88)$ \\
\hline NSCLC & Adenocarcinoma & 93 \\
\hline & Squamous carcinoma & 54 \\
\hline SCLC & Other NSCLC & 21 \\
\hline Stage & 18 \\
\hline & I & 3 \\
\hline & II+IV & 44 \\
\hline Blooddraw before resection & 18 \\
\hline \hline Blooddraw after resection & 4 \\
\hline \hline BNLCC-benign SPN & 96 \\
\hline M/F & 0 \\
\hline Mean age year (range) & 29 \\
\hline Blooddraw before resection & $15 / 14$ \\
\hline Blooddraw after resection & $56(31 \sim 81)$ \\
\hline \hline GELCC-Lung cancer & 29 \\
\hline M/F & 0 \\
\hline Mean age year (range) & 44 \\
\hline \hline Healthy donor & $18 / 26$ \\
\hline Mean age year (range) & $61(47 \sim 70)$ \\
\hline
\end{tabular}

patients with benign SPNs from the BNLCC $(P=$ $0.003)$. The optimum cutoff value of plasma sPLA2-IIa by ROC analysis was $2.4 \mathrm{ng} / \mathrm{ml}$, which resulted in $64 \%$ sensitivity and $86 \%$ specificity for predicting lung cancer (AUC: $0.79 ; 95 \%$ CI: $0.69 \sim 0.90$ ) (Table 3a). On the other hand, among 20 healthy donors, the levels of plasma sPLA2-IIa were undetecTable in 15 healthy donors, while those of the remaining 5 donors ranged up to $275 \mathrm{pg} / \mathrm{ml}$ (see Additional file 3). Age was not significantly associated with the level of plasma sPLA2-IIa in this healthy donor cohort (Table 1). ROC analysis of the plasma sPLA2-IIa levels in 96 lung cancer samples from the BNLCC and 20 healthy donor samples revealed an AUC as 1.0 (95\% CI: $1.0 \sim 1.0$ ) (Figure 2a).

Further analysis revealed that plasma sPLA2-IIa was significantly higher in T2 stage lung cancer $(n=18)$ relative to T1 stage lung cancer $(n=44)$ from the BNLCC (Two tailed t test: $P=0.005$ ) (Figure $1 \mathrm{~b}$ and see Additional file 1). The optimum cutoff value of plasma sPLA2-IIa by ROC analysis was $2.4 \mathrm{ng} / \mathrm{ml}$, which resulted in $67 \%$ sensitivity for predicting T2 stage lung cancer (AUC: 0.86; 95\% CI: $0.65 \sim 0.96$ ), as compared with $45 \%$ sensitivity for predicting $\mathrm{T} 1$ stage lung cancer (Table $3 \mathrm{a}$ and Figure 2c). High levels of plasma sPLA2- 
Table 2 Plasma sPLA2-Ila levels and diagnosis in patients with benign SPNs from BNLCC

\begin{tabular}{|c|c|c|}
\hline Sample & sPLA2-Ila (pg/ml) & Diagnosis \\
\hline 1 & 1039.2 & $0.9 \mathrm{~cm}$ nodule and heavy smoker \\
\hline 2 & 1589.2 & $1.3 \times 1.4 \times 1.1 \mathrm{~cm}$ subpleural nodule, necrotizing granuloma \\
\hline 3 & 480.83 & Nodule $2 \mathrm{~cm}$ \\
\hline 4 & 8980.8 & Necrotizing granulomatous \\
\hline 5 & 1030.8 & Nonnecrotizing granulomas \\
\hline 6 & 1105.8 & Abscess colonized with fungal hyphae \\
\hline 7 & 3680.8 & Nodule with organizing pneumonia pattern of lung injury \\
\hline 8 & 922.5 & Caseating granulomas with emphysematous changes \\
\hline 9 & 797.5 & Nodules of caseating granulomas \\
\hline 10 & 2372.5 & Necrotizing granuloma with fungal organisms \\
\hline 11 & 1789.2 & Peribronchial tumorlet-2 $\mathrm{mm}$ and focal parenchymal fibrosis \\
\hline 12 & 580.83 & Necrotizing granuloma with fungal organisms \\
\hline 13 & 2305.8 & Necrotizing granuloma $(2 \times 1.7 \times 1.3 \mathrm{~cm})$ \\
\hline 14 & 872.5 & Broncial and broncheolar ectasis with fibrosis and chronic inflammation c/w bronchiectasis \\
\hline 15 & 2714.2 & Bronchiolitis obliterans organizing pneumonia \\
\hline 16 & 714.17 & Focal fibrosis and chronic inflammation and reactive pneumocyte hyperplasia \\
\hline 17 & 2105.8 & Caseating granulomas with fungal elements \\
\hline 18 & 2422.17 & Myolipomatous polyp \\
\hline 19 & 1226.52 & Active granulomatous inflammation and possible sarcoidosis \\
\hline 20 & 2217.83 & Neurofibroma, $4.5 \times 3.5 \mathrm{~cm}$ \\
\hline 21 & 1804.78 & Active non-caseating granulomas \\
\hline 22 & 430.87 & Necrotizing granuloma with fungal organisms \\
\hline 23 & 3878.7 & Caseating necrotizing granulomas with fungal elements \\
\hline 24 & 835.22 & Non-caseating granulomas with fungal elements \\
\hline 25 & 572.5 & Necrotizing granulomatous inflammation with fungal organisms consistent with Aspergillus \\
\hline 26 & 1553.75 & Necrotizing granulomas with fungal yeast forms consistent with Histoplasma \\
\hline 27 & 816.25 & Organizing suppurative bronchopneumonia with pleural adhesions \\
\hline 28 & 1328.75 & Presented with sTable lung nodule \\
\hline 29 & 1228.13 & necrotizing granuloma and Langerhans' cell histiocytosis \\
\hline
\end{tabular}

*The data in bold is higher than the cutoff value of the blood test.

IIa were also associated with a decreased overall survival (Unpaired t test with Welch correction: $P=0.0457$ ) (see Additional file 1). The mean overall survival year for high sPLA2-IIa (> $2.4 \mathrm{ng} / \mathrm{ml}, n=6)$ was $1.8 \pm 1.3$ years, while the mean overall survival year for low sPLA2-IIa $(<2.4 \mathrm{ng} / \mathrm{ml}, n=11)$ was $3.3 \pm 1.9$ years.

Given the heterogeneous nature of cancer, the combined blood tests including a panel of biomarkers will increase the sensitivity for cancer prediction. Carcinoembryonic Antigen (CEA) and Cytokeratin-19 fragment (Cyfra 21.1) with the optimum cutoff value $6 \mathrm{ng} /$ $\mathrm{ml}$ and $3.3 \mathrm{ng} / \mathrm{ml}$, respectively, are two best biomarkers for predicting NSCLC currently under investigation $[12,26,27]$. Positive prediction for the presence of lung cancer by the combined blood tests was defined as one or more biomarkers higher than their cutoff values. We found that a combination of sPLA2-IIa $(2.4 \mathrm{ng} / \mathrm{ml}$ cutoff value), Cyfra 21.1 (3.3 ng/ml cutoff value), and CEA (6 $\mathrm{ng} / \mathrm{ml}$ cutoff value) tests increased the sensitivity for lung cancer prediction up to $62 \%$ from $48 \%$ by sPLA2IIa test alone for 96 cancers relative to 29 patients with benign SPNs from the BNLCC (Table $3 \mathrm{~b}$ and see Additional file 1 and 4). Furthermore, the combined tests increased the sensitivity for lung cancer prediction up to $59 \%$ and $72 \%$ from $45 \%$ and $67 \%$ by sPLA2-IIa test alone for $44 \mathrm{~T} 1$ stage cancers and $18 \mathrm{~T} 2$ stage cancers relative to 29 patients with benign SPNs, respectively. CEA and Cyfra 21.1 test alone had only $20 \%$ and $14 \%$ sensitivity, respectively (Table $3 \mathrm{~b}$ ).

Among the 5 patients with benign lung nodules and higher level of plasma sPLA2-IIa than the cutoff value $2.4 \mathrm{ng} / \mathrm{ml}$, two patient suffered from localized pneumonia, one patient suffered from myolipomatous polyp, and the other two patients were diagnosed with 


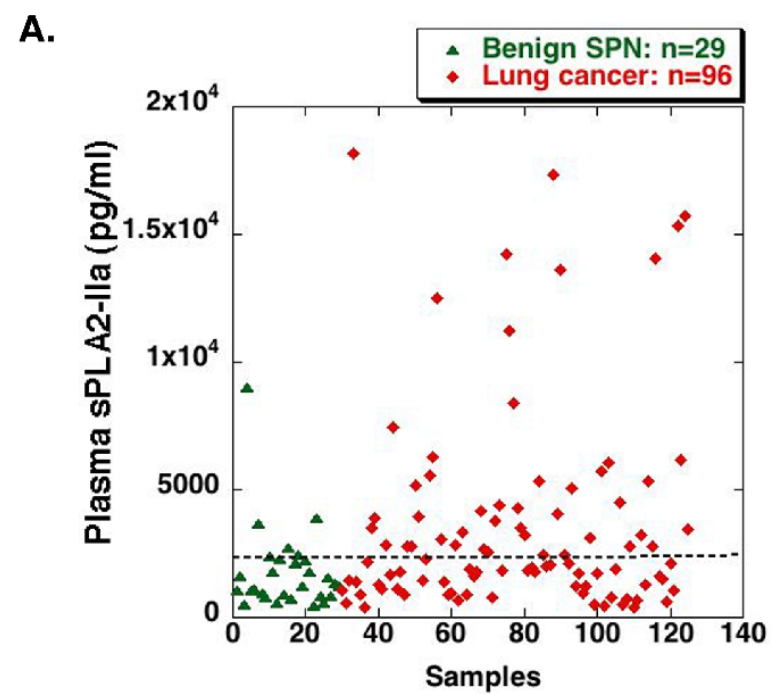

B.

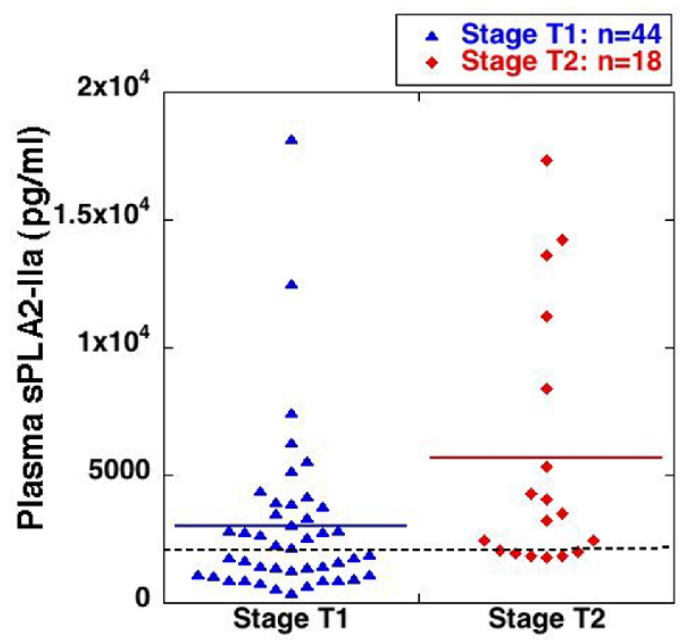

Figure 1 High levels of plasma SPLA2-Ila are associated with lung cancer as compared with benign lung nodule. (a) Plasma samples were diluted ten times and then subjected to ELISA analysis for SPLA2-lla levels in duplicate of each sample. The average of the duplicate samples was calculated against to the standard curve in each experiment and presented as $\mathrm{pg} / \mathrm{ml}$ sPLA2- Ila. (b) High levels of plasma sPLA2-lla are significantly associated with T2 lung cancer relative to $\mathrm{T} 1$ stage lung cancer. The dotted line indicates the optimum cutoff value of $2.4 \mathrm{ng} / \mathrm{ml}$

necrotizing granulomas (Table 2). This finding indicated that active localized inflammation can occasionally lead to a moderate increased plasma sPLA2-IIa. Furthermore, our data demonstrated that there was an increased basal level of plasma sPLA2-IIa in patients with SPNs relative to those in healthy donors, which may result from SPNs and chronic inflammation.

Our data strongly suggest that plasma sPLA2-IIa can serve as a biomarker to predict more than $48 \%$ of $\mathrm{T} 1$ stage lung cancers and up to $67 \%$ of T2 stage lung cancer relative to patients with benign SPNs, although the plasma sPLA2-IIa is elevated occasionally in patients of benign SPNs. sPLA2-IIa is the best biomarker relative to Cyfra 21.1 and CEA, and the combined sPLA2-IIa, Cyfra 21.1 and CEA tests increase the sensitivity for lung cancer prediction relative to sPLA2-IIa test alone. In addition, plasma sPLA2-IIa may potentially serve as a poor prognosis biomarker for lung cancer.

\section{sPLA2-lla is overexpressed in lung cancer specimens}

Among 100 core lung biopsies examined by IHC, sPLA2-IIa was overexpressed in $100 \%$ of squamous cell carcinoma (20 cores), adenocarcinoma (20 cores), and bronchioalveolar carcinoma (10 cores), in $70 \%$ of small cell carcinoma (10 cores), and in $90 \%$ of metastatic squamous cell carcinoma (10 cores) (Figure 3a-e), but not detected in atypical carcinoid (5 cores) (Figure $3 \mathrm{f}$ ). sPLA2-IIa was not detected in inflammatory pseudo tumor (5 cores), tuberculosis (5 cores), and normal lung tissue (15 cores) (Figure 3g-h). Expression of sPLA2-IIa in infiltrating macrophages and endothelial cells of new blood vessels in inflammatory pseudo tumors (Figure $3 \mathrm{~g}$ ) implicated an underlying mechanism of localized inflammation as the cause of occasional elevated levels of plasma sPLA2-IIa in patients with benign lesions (Table 2). We also found that sPLA2-IIa was overexpressed in lung cancer tissue, but not the adjacent normal type I and II epithelial cells in the spontaneous mouse lung cancer from SP-C/TAg transgenic mice, in which the transgene SV40 early region (TAg) gene was driven by a $3.7 \mathrm{~kb}$ promoter of human surfactant protein C (SP-C) gene (Figure 3i) [28,29]. These data confirmed that sPLA1-IIa was overexpressed in lung cancer cells, but not in normal alveolar epithelial cells.

\section{Discussion}

With increased sensitivity of imaging technology, such as low dose spiral computed tomography (LDCT), lung cancer can be detected at an earlier stage [2]. Recently, lung cancer screening with $\mathrm{CT}$ has been shown to detect lung tumors earlier and decrease lung cancer mortality [30]. One of the problems with the use of CT screening is the number of false positive with up to $25 \%$ of the subjects in the lung cancer screening trials having nodules, most of which are benign. Given the epidemic of histoplasmosis in the Ohio valley, we found that among 132 people enrolled in a pilot lung cancer screening project, $61 \%$ of subjects had nodules, most of which were benign [5]. If lung cancer screening with $C T$ becomes standard, there will be a large number of nodules that will need to be evaluated. Monitoring these nodules usually requires repeated CT scans at 3, 6, 9, 12, 24 months based on the sizes of SPNs [6]. An 
Table 3 High level of plasma sPLA2-Ila predicts lung cancer

\begin{tabular}{|c|c|c|c|c|c|}
\hline \multicolumn{6}{|c|}{ Table 3a: Determination of plasma sPLA2-Ila to predict lung cancer by ROC analysis. } \\
\hline Plasma sPLA2-Ila & $<2.4 \mathrm{ng} / \mathrm{ml}$ & $>2.4 \mathrm{ng} / \mathrm{ml}$ & Total case\# & \%Senstivity & \%Specificity \\
\hline \multicolumn{6}{|c|}{ BNLCC lung cancer vs. benign SPN } \\
\hline Benign SPN & 24 & 5 & 29 & & 86 \\
\hline Lung cancer & 50 & 46 & 96 & 48 & \\
\hline Stage 1 lung cancer & 24 & 20 & 44 & 45 & \\
\hline Stage 2 lung cancer & 6 & 12 & 18 & 67 & \\
\hline \multicolumn{6}{|c|}{ GELCC lung cancer vs. benign SPN } \\
\hline Lung cancer & 16 & 28 & 44 & 64 & \\
\hline \multicolumn{6}{|c|}{$\begin{array}{l}\text { Table 3b: Combined sPLA2-IIa, CEA, and Cyfra21.1 blood tests increase the sentisitivity } \\
\text { to predict lung cancer. }\end{array}$} \\
\hline sPLA2-Ila & $<2.4 \mathrm{ng} / \mathrm{ml}$ & $>2.4 \mathrm{ng} / \mathrm{ml}$ & & & \\
\hline CEA & $<6.0 \mathrm{ng} / \mathrm{ml}$ & $>6.0 \mathrm{ng} / \mathrm{ml}$ & Total case\# & \%Senstivity & \%Specificity \\
\hline Cyfra21.1 & $<3.3 \mathrm{ng} / \mathrm{ml}$ & $>3.3 \mathrm{ng} / \mathrm{ml}$ & & & \\
\hline \multicolumn{6}{|c|}{ BNLCC lung cancer vs. benign SPN } \\
\hline Benign SPN & 22 & 7 & 29 & & 76 \\
\hline Lung cancer & 36 & 60 & 96 & 63 & \\
\hline Stage 1 lung cancer & 18 & 26 & 44 & 59 & \\
\hline Stage 2 lung cancer & 5 & 13 & 18 & 72 & \\
\hline CEA & $<6.0 \mathrm{ng} / \mathrm{ml}$ & $>6.0 \mathrm{ng} / \mathrm{ml}$ & Total case\# & \%Senstivity & \%Specificity \\
\hline \multicolumn{6}{|c|}{ BNLCC lung cancer vs. benign SPN } \\
\hline Benign SPN & 28 & 1 & 29 & & 97 \\
\hline Lung cancer & 77 & 19 & 96 & 20 & \\
\hline Cyfra21.1 & $<3.3 \mathrm{ng} / \mathrm{ml}$ & $>3.3 \mathrm{ng} / \mathrm{ml}$ & Total case\# & \%Senstivity & \%Specificity \\
\hline \multicolumn{6}{|c|}{ BNLCC lung cancer vs. benign SPN } \\
\hline Benign SPN & 27 & 2 & 29 & & 93 \\
\hline Lung cancer & 83 & 13 & 96 & 14 & \\
\hline
\end{tabular}

increase in the size of a SPN is currently the parameter used to predict the presence of lung cancer. This repeated CT scan results in radiation exposure as well as anxiety. Patients may also undergo invasive procedures for diagnosis such as bronchoscopy, CT-guided fine needle aspiration, or thoracoscopic resection. It will become critical to have more effective ways to determine which nodules are most likely malignant.

We recently reported that there is an elevated level of plasma sPLA2-IIa in prostate cancer patients [17]. The current study showed that lung cancer tissues overexpress SPLA2-IIa and that patients with lung cancer have elevated levels of plasma sPLA2-IIa. The expression of the sPLA2-IIa gene is not tissue-specific or cancer-specific [17]. It was reported that the levels of plasma sPLA2IIa are elevated with bacterial and viral infection or IL-2 infusion [31,32] and in coronary heart disease [33-35]. However, a recent clinical study including more than 500 patients showed that there is no significant alteration in plasma level of sPLA2-IIa protein among patients with coronary artery disease relative to healthy controls [34]. In consideration of these complications, we included some patients with inflammatory nodules of the lung as controls. We found an increased basal level of plasma sPLA2-IIa in these controls relative to those in healthy donors, which may be a result of chronic inflammation due to fungal infection and pneumonia. This active localized inflammation can occasionally lead to a moderate increased level of plasma sPLA2IIa. Nevertheless, a significant high level of plasma sPLA2-IIa as a result of lung cancer can predict more than $48 \%$ of early stage lung cancers and up to $67 \%$ of T2 stage lung tumors with $86 \%$ specificity. sPLA2-IIa blood test has potential to help with the decision algorithm and determine the timing of subsequent $\mathrm{CT}$ scans and potential biopsy of concerning nodules.

One concern for using sPLA2-IIa as a lung cancer biomarker is that it lacks cancer specificity. This is one of the common features shared by all biomarkers currently in clinical use or under development and is simply due to the fact that genes contributing to cancer development overlap with those for other metabolic diseases, 


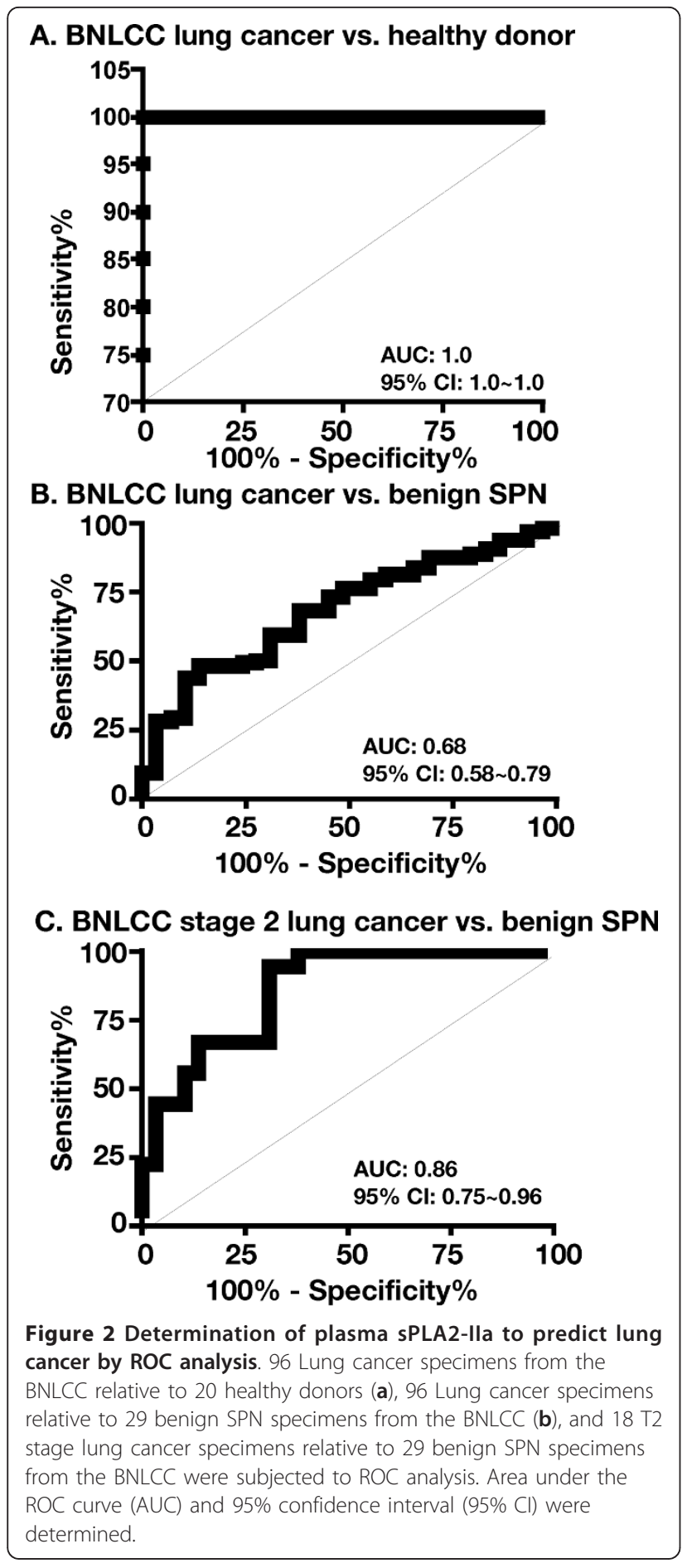

such as diabetes, obesity, and inflammation. In addition, the sensitivity of these plasma biomarkers is usually not very high, especially for early stages of cancer, which is partially due to the heterogeneous nature of cancer. Only a few plasma biomarkers are currently used to screen and diagnose cancers in clinical practice, including PSA, $\alpha$-fetoprotein, CA19-9, CA125, and CEA
[9-11]. None of these plasma biomarkers are cancer-specific [11]. For example, PSA is tissue-specific but not cancer-specific and has only $21 \%$ sensitivity with $4 \mathrm{ng} /$ $\mathrm{ml}$ as the cutoff value [36]. Plasma PSA are elevated in benign diseases, such as in $30 \sim 50 \%$ BPH patients, which leads to low specificity [37]. On the other hand, many prostate cancers do not lead to a high PSA and fail to be detected in PSA screening, which also contributes to low sensitivity [37-41]. $\alpha$-fetoprotein (AFP) for hepatocellular carcinoma has $65 \%$ sensitivity and $89 \%$ specificity, while the addition of VEGF and fucosidase (AFU) tests can increase the sensitivity up to $100 \%$ $[42,43]$. Furthermore, it is also noted that sensitivity of plasma biomarkers, such as CA125, is increased with advanced cancer stages, which is also consistent with our observation of plasma sPLA2-IIa for lung cancer [44].

A few serum biomarkers for lung cancer are currently under investigation, including Cyfra 21.1 and CEA for NSCLC and neuron-specific enolase (NSE) for SCLC $[12,26,27]$. Our data showed that none of these lung cancer biomarkers, based on the cutoff value reported, has high sensitivity to predict an early stage lung cancer [45]. However, the combined test of sPLA2-IIa, Cyfra 21.1 and CEA increases the power for lung cancer prediction relative to sPLA2-IIa test alone. We did not examine NSE, since there are only three SCLC specimens in the BNLCC cohort. Although Cyfra 21.1 is preferentially for squamous cell carcinoma, we did not find that Cyfra 21.1 shows a high sensitivity for squamous cell carcinoma. Given the heterogeneous nature of cancer and heterogeneous gene overexpression from one cancer to another, a combined blood test including a few plasma biomarkers is essential to increase the sensitivity to predict an early stage lung cancer.

In summary, we demonstrated that lung cancer tissues overexpress sPLA2-IIa and there is an elevated level of plasma sPLA2-IIa in lung cancer patients. Multiple lines of evidence support the notion that plasma sPLA2-IIa may represent a novel biomarker for lung cancer: 1 ) sPLA2-IIa is overexpressed in all squamous cell carcinoma, adenocarcinoma, and bronchioalveolar carcinoma examined and in majority of small cell carcinoma; 2) High levels of plasma sPLA2-IIa predict approximately $48 \%$ of early stage lung cancers and up to $67 \%$ of T2 stage lung cancers relative to patients with benign SPN; 3) High levels of plasma sPLA2-IIa are associated with advanced lung cancer stages and a decreased overall cancer survival; 4) the combined sPLA2-IIa, Cyfra 21.1 and CEA tests increase the power for lung cancer prediction relative to SPLA2-IIa test alone; 5) The combined lung cancer blood tests have potential to help with the decision algorithm of lung cancer diagnosis 


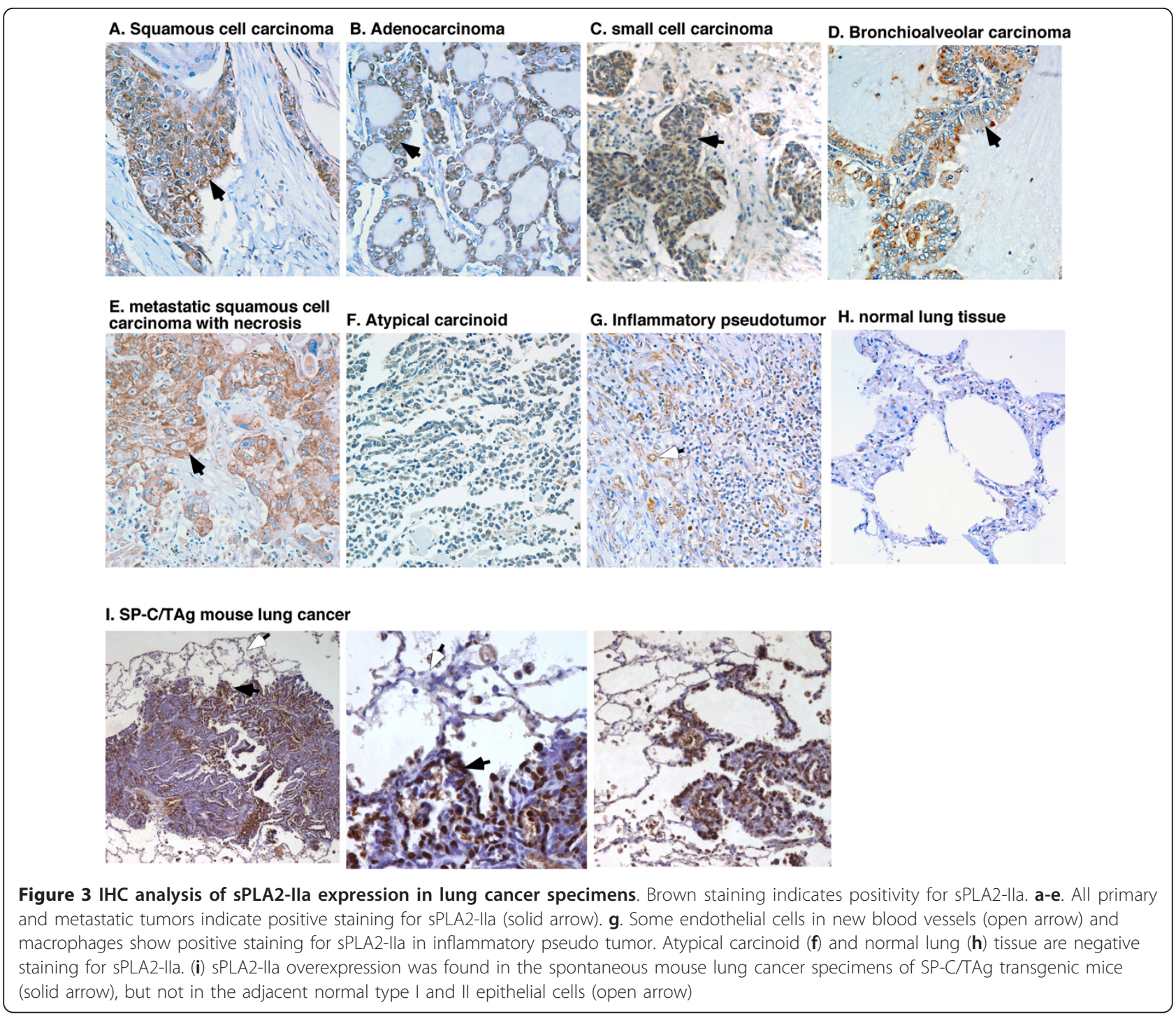

and reduce the number of $\mathrm{CT}$ scan and radiation exposure.

\section{Conclusions}

This study uncovered that plasma sPLA2-IIa is a potential biomarker for lung cancer. sPLA2-IIa in combination with lung cancer biomarkers Cyfra 21.1 and CEA will help with the decision algorithm for diagnosis of an early stage lung cancer in patients with SPNs and poor prognosis. Application of this combined biomarker test will increase lung cancer survival, reduce painful and costly resection of SPN, and reduce radiation exposure by repeated CT exam for SPN patients.

\section{Additional material}

Additional file 1: Plasma SPLA2-Ila level in healthy donors.
Additional file 2: The levels of plasma sPLA2-lla, Cyfra21.1, and CEA in lung cancer patients from the BNLCC.

Additional file 3: The levels of plasma SPLA2-Ila in lung cancer patients from the GELCC

Additional file 4: Plasma sPLA2-lla, Cyfra21.1, and CEA levels and diagnosis in patients with benign SPNs from BNLCC.

\section{Abbreviations}

SPLA2-Ila: Secretory phospholipase A2 group Ila; SPNs: Solitary pulmonary nodules; NSCLC: Non-small cell lung cancer; SCLC: Small cell lung cancer; Cyfra 21.1: Cytokeratin-19 fragment; CEA: Carcinoembryonic antigen; NSE: Neuron-specific enolase; ROC: Receiver operating characteristic; LDCT: Low dose spiral computed tomography

\section{Acknowledgements and funding}

Supported by grants from University of Cincinnati Cancer Center Foundation and NIH grants R01 CA119935 and CA131137. UC cancer center tissue bank. Patent pending: 35 U.S.C. §119. 


\section{Author details}

'Department of Cancer and Cell Biology, University of Cincinnati College of Medicine, Cincinnati, OH 45237, USA. ² Department of Pathology, University of Cincinnati College of Medicine, UC Metabolic Diseases Institute, 2120 E. Galbraith Road, Building A, Room 259, Cincinnati, OH 45237-0507, USA. ${ }^{3}$ Department of Environmental Health, University of Cincinnati College of Medicine, Cincinnati, OH 45237, USA. ${ }^{4}$ Department of Medicine, University of Cincinnati College of Medicine, Cincinnati, OH 45237, USA. ${ }^{5}$ Department of Surgery, University of Cincinnati College of Medicine, Cincinnati, OH 45237, USA.

\section{Authors' contributions}

EK, MA, KW, PC, SP, ZD, SS, and TM participated in patient specimens and data collection. JW and KW performed pathology analysis. PS and LL performed statistical analysis. YL carried out immunohistochemistry analysis and ELISA. MA, ZD, SS, and SL contributed to conception and design of study and interpretation of data. All authors read and approved the final manuscript.

\section{Competing interests}

The authors declare that they have no competing interests.

Received: 30 August 2011 Accepted: 9 December 2011

Published: 9 December 2011

\section{References}

1. Jemal A, Siegel R, Ward E, Hao Y, Xu J, Thun MJ: Cancer statistics, 2009. CA: A CancerJ Clin 2009, 59(4):225-249.

2. Detterbeck FC, Boffa DJ, Tanoue LT: The new lung cancer staging system. Chest 2009, 136(1):260-271.

3. Henschke Cl, McCauley DI, Yankelevitz DF, Naidich DP, McGuinness G, Miettinen OS, Libby DM, Pasmantier MW, Koizumi J, Altorki NK, et al: Early Lung Cancer Action Project: overall design and findings from baseline screening. Lancet 1999, 354(9173):99-105.

4. Wahidi MM, Govert JA, Goudar RK, Gould MK, McCrory DC: Evidence for the treatment of patients with pulmonary nodules: when is it lung cancer?: ACCP evidence-based clinical practice guidelines (2nd edition). Chest 2007, 132(3 Suppl):94S-107S.

5. Starnes SL, Reed MF, Meyer CA, Shipley RT, Jazieh AR, Pina EM, Redmond K, Huffman LC, Pandalai PK, Howington JA: Lung cancer screening with lowdose $C T$ in an area endemic for Histoplasma Capsulatum: minimizing invasive procedures for benign nodules. J Thorac Cardiovasc Surg 2011, 141:688-693.

6. Gould MK, Fletcher J, lannettoni MD, Lynch WR, Midthun DE, Naidich DP, Ost DE: Evaluation of patients with pulmonary nodules: when is it lung cancer?: ACCP evidence-based clinical practice guidelines. Chest, 2 2007, 132(3 Suppl):108S-130S.

7. Oxnard GR, Zhao B, Sima CS, Ginsberg MS, James LP, Lefkowitz RA, Guo P, Kris MG, Schwartz LH, Riely GJ: Variability of Lung Tumor Measurements on Repeat Computed Tomography Scans Taken Within 15 Minutes. J Clin Oncol 2011.

8. Edey AJ, Hansell DM: Incidentally detected small pulmonary nodules on CT. Clin Radiol 2009, 64(9):872-884.

9. Ghosal R, Kloer P, Lewis KE: A review of novel biological tools used in screening for the early detection of lung cancer. Postgrad Med J 2009, 85(1005):358-363.

10. Amur S, Frueh FW, Lesko L, Huang SM: Integration and use of biomarkers in drug development, regulation and clinical practice: a US regulatory perspective. Biomark Med 2008, 2(3):305-311.

11. Sturgeon CM, Lai LC, Duffy MJ: Serum tumour markers: how to order and interpret them. BMJ 2009, 339:b3527.

12. Tufman A, Huber RM: Biological markers in lung cancer: A clinician's perspective. Cancer Biomark 2010, 6(3-4):123-135.

13. Cummings BS: Phospholipase A2 as targets for anti-cancer drugs. Biochem Pharmacol 2007, 74(7):949-959.

14. Triggiani M, Granata F, Giannattasio G, Marone G: Secretory phospholipases A2 in inflammatory and allergic diseases: not just enzymes. The J Allergy Clin Immunol 2005, 116(5):1000-1006.

15. Meyer AM, Dwyer-Nield LD, Hurteau GJ, Keith RL, O'Leary E, You M, Bonventre JV, Nemenoff RA, Malkinson AM: Decreased lung tumorigenesis in mice genetically deficient in cytosolic phospholipase A2. Carcinog 2004, 25(8):1517-1524.

16. Antonio V, Brouillet A, Janvier B, Monne C, Bereziat G, Andreani M, Raymondjean M: Transcriptional regulation of the rat type IIA phospholipase A2 gene by CAMP and interleukin-1 beta in vascular smooth muscle cells: interplay of the CCAAT/enhancer binding protein (C/EBP), nuclear factor-kappaB and Ets transcription factors. The Biochem J 2002, 368(Pt 2):415-424.

17. Dong Z, Liu Y, Scott KF, Levin L, Gaitonde K, Bracken RB, Burk B, Zhai Q Wang J, Oleksowicz L, et al: Secretory phospholipase A2-lla is involved in prostate cancer progression and may potentially serve as a biomarker for Prostate Cancer. Carcinog 2010, 31:1948-1955.

18. Kallajoki M, Alanen KA, Nevalainen M, Nevalainen TJ: Group II phospholipase A2 in human male reproductive organs and genital tumors. The Prostate 1998, 35(4):263-272.

19. Jiang J, Neubauer BL, Graff JR, Chedid M, Thomas JE, Roehm NW, Zhang S, Eckert GJ, Koch MO, Eble JN, et al: Expression of group IIA secretory phospholipase A2 is elevated in prostatic intraepithelial neoplasia and adenocarcinoma. The Am J Pathol 2002, 160(2):667-671.

20. Graff JR, Konicek BW, Deddens JA, Chedid M, Hurst BM, Colligan B, Neubauer BL, Carter HW, Carter JH: Expression of group lla secretory phospholipase A2 increases with prostate tumor grade. Clin Cancer Res 2001, 7(12):3857-3861.

21. Sved P, Scott KF, McLeod D, King NJ, Singh J, Tsatralis T, Nikolov B, Boulas J, Nallan L, Gelb MH, et al: Oncogenic action of secreted phospholipase A2 in prostate cancer. Cancer Res 2004, 64(19):6934-6940.

22. Dong Z, Liu Y, Levin L, Oleksowicz L, Wang J, Lu S: Vav3 oncogene is involved in regulation of secretory phospholipase A2-lla expression in prostate cancer. Oncology Reports 2011, 25(6):1511-6.

23. Oleksowicz L, Liu Y, Bracken RB, Gaitonde K, Burke B, Succop P, Levin L, Dong ZY, Lu S: Secretory Phospholipase A2-lla is a Target Gene of the HER/HER2-Elicited Pathway and Potential Plasma Biomarker for Poor Prognosis of Prostate Cancer. The Prostate 2011.

24. Dong ZY, Liu Y, Lu S, Wang A, Lee K, Wang LH, Revelo M, Lu S: Vav3 oncogene is overexpressed and regulates cell growth and androgen receptor activity in human prostate cancer. Mol Endo 2006, 20:2315-2325.

25. Schisterman EF, Perkins NJ, Liu A, Bondell H: Optimal cut-point and its corresponding Youden Index to discriminate individuals using pooled blood samples. Epidemiol 2005, 16(1):73-81.

26. Molina R, Filella X, Auge JM, Fuentes R, Bover I, Rifa J, Moreno V, Canals E, Vinolas N, Marquez A, et al: Tumor markers (CEA, CA 125, CYFRA 21-1, SCC and NSE) in patients with non-small cell lung cancer as an aid in histological diagnosis and prognosis. Comparison with the main clinical and pathological prognostic factors. Tumour Biol 2003, 24(4):209-218.

27. Wieskopf B, Demangeat C, Purohit A, Stenger R, Gries P, Kreisman $H_{\text {, }}$ Quoix E: Cyfra 21-1 as a biologic marker of non-small cell lung cancer. Evaluation of sensitivity, specificity, and prognostic role. Chest 1995, 108(1):163-169.

28. Glasser SW, Korfhagen TR, Wert SE, Bruno MD, McWilliams KM, Vorbroker DK, Whitsett JA: Genetic element from human surfactant protein SP-C gene confers bronchiolar-alveolar cell specificity in transgenic mice. Am J Physiol 1991, 261(4 Pt 1):L349-356.

29. Wikenheiser KA, Clark JC, Linnoila RI, Stahlman MT, Whitsett JA: Simian virus 40 large $T$ antigen directed by transcriptional elements of the human surfactant protein $\mathrm{C}$ gene produces pulmonary adenocarcinomas in transgenic mice. Cancer Res 1992, 52(19):5342-5352.

30. Team TNLSTR: Reduced lung-cancer mortality with low-dose computed tomographic screening. The New England J Med 2011, 365(5):395-409.

31. Wolbink GJ, Schalkwijk C, Baars JW, Wagstaff J, van den Bosch H, Hack CE: Therapy with interleukin-2 induces the systemic release of phospholipase-A2. Cancer Immunol Immunother 1995, 41(5):287-292.

32. Juffrie M, Meer GM, Hack CE, Haasnoot K, Sutaryo, Veerman AJ, Thijs LG: Inflammatory mediators in dengue virus infection in children: interleukin- 6 and its relation to C-reactive protein and secretory phospholipase A2. The Am J Trop Med Hyg 2001, 65(1):70-75.

33. Ogawa M, Sato N, Endo S, Kojika M, Yaegashi Y, Kimura Y, Ikeda K, Iwaya T: Group IIA-soluble phospholipase A2 levels in patients with infections after esophageal cancer surgery. Surgery Today 2005, 35(11):912-918.

34. Wootton PT, Drenos F, Cooper JA, Thompson SR, Stephens JW, HurtCamejo E, Wiklund O, Humphries SE, Talmud PJ: Tagging-SNP haplotype analysis of the secretory PLA2lla gene PLA2G2A shows strong 
association with serum levels of SPLA2lla: results from the UDACS study. Human Mol Genet 2006, 15(2):355-361.

35. Yamaguchi O, Sugimura K, Ishizuka K, Suzuki K, Hasegawa K, Ohtsuka K, Honma T, Asakura H: Correlation between serum phospholipase A(2) IIA levels and histological activity in patients with ulcerative colitis. Int $J$ Colorectal Dis 2002, 17(5):311-316.

36. Serdar MA, Oguz O, Olgun A, Seckin B, Ilgan S, Hasimi A, Salih M, Peker F, Kutluay T: Diagnostic approach to prostate cancer using total prostate specific antigen-based parameters together. Ann Clin Lab Sci 2002, 32(1):22-30.

37. Catalona WJ, Smith DS, Ratliff TL, Dodds KM, Coplen DE, Yuan JJ, Petros JA, Andriole GL: Measurement of prostate-specific antigen in serum as a screening test for prostate cancer. The New England J Med 1991 324(17):1156-1161.

38. Roddam AW, Duffy MJ, Hamdy FC, Ward AM, Patnick J, Price CP, Rimmer J, Sturgeon C, White P, Allen NE: Use of prostate-specific antigen (PSA) isoforms for the detection of prostate cancer in men with a PSA level of 2-10 ng/ml: systematic review and meta-analysis. European urology 2005, 48(3):386-399, discussion 398-389.

39. Catalona WJ, Ramos CG, Carvalhal GF, Yan Y: Lowering PSA cutoffs to enhance detection of curable prostate cancer. Urology 2000, 55(6):791-795.

40. Thompson IM, Pauler DK, Goodman PJ, Tangen CM, Lucia MS, Parnes HL, Minasian LM, Ford LG, Lippman SM, Crawford ED, et al: Prevalence of prostate cancer among men with a prostate-specific antigen level $<$ or $=4.0 \mathrm{ng}$ per milliliter. The New England J Med 2004, 350(22):2239-2246.

41. Gilbert SM, Cavallo CB, Kahane H, Lowe FC: Evidence suggesting PSA cutpoint of $2.5 \mathrm{ng} / \mathrm{mL}$ for prompting prostate biopsy: review of 36,316 biopsies. Urology 2005, 65(3):549-553.

42. Soresi M, Magliarisi C, Campagna P, Leto G, Bonfissuto G, Riili A, Carroccio A, Sesti R, Tripi S, Montalto G: Usefulness of alpha-fetoprotein in the diagnosis of hepatocellular carcinoma. Anticancer Res 2003, 23(2C):1747-1753.

43. el-Houseini ME, Mohammed MS, Elshemey WM, Hussein TD, Desouky OS, Elsayed AA: Enhanced detection of hepatocellular carcinoma. Cancer Control 2005, 12(4):248-253.

44. Terry KL, Sluss PM, Skates SJ, Mok SC, Ye B, Vitonis AF, Cramer DW: Blood and urine markers for ovarian cancer: a comprehensive review. Dis Markers 2004, 20(2):53-70

45. Buchen L: Cancer: Missing the mark. Nature 2011, 471(7339):428-432.

\section{Pre-publication history}

The pre-publication history for this paper can be accessed here: http://www.biomedcentral.com/1471-2407/11/513/prepub

\section{doi:10.1186/1471-2407-11-513}

Cite this article as: Kupert et al:: Plasma secretory phospholipase A2-lla as a potential biomarker for lung cancer in patients with solitary pulmonary nodules. BMC Cancer 2011 11:513.

\section{Submit your next manuscript to BioMed Central and take full advantage of:}

- Convenient online submission

- Thorough peer review

- No space constraints or color figure charges

- Immediate publication on acceptance

- Inclusion in PubMed, CAS, Scopus and Google Scholar

- Research which is freely available for redistribution

Submit your manuscript at www.biomedcentral.com/submit
Biomed Central 